\title{
Article \\ Advanced Modelling and Risk Analysis of RC Buildings with Sliding Isolation Systems Designed by the Italian Seismic Code
}

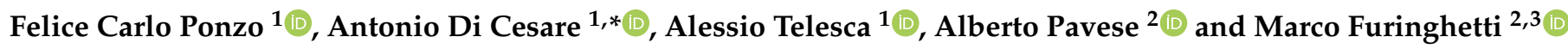 \\ 1 School of Engineering, University of Basilicata, Viale dell'Ateneo Lucano 10, 85100 Potenza, Italy; \\ felice.ponzo@unibas.it (F.C.P.); alessio.telesca@unibas.it (A.T.) \\ 2 Department of Civil Engineering and Architecture, University of Pavia, Via Ferrata, 3, 27100 Pavia, Italy; \\ a.pavese@unipv.it (A.P.); marco.furinghetti@unipv.it (M.F.) \\ 3 EUCENTRE, European Centre for Training and Research in Earthquake Engineering, Via Ferrata, 1, \\ 27100 Pavia, Italy \\ * Correspondence: antonio.dicesare@unibas.it
}

Citation: Ponzo, F.C.; Di Cesare, A.; Telesca, A.; Pavese, A.; Furinghetti, M. Advanced Modelling and Risk Analysis of RC Buildings with Sliding Isolation Systems Designed by the Italian Seismic Code. Appl. Sci. 2021, 11, 1938. https://doi.org/10.3390/ app11041938

Academic Editor: Panagiotis

G. Asteris

Received: 14 January 2021

Accepted: 18 February 2021

Published: 23 February 2021

Publisher's Note: MDPI stays neutral with regard to jurisdictional claims in published maps and institutional affiliations.

Copyright: (c) 2021 by the authors. Licensee MDPI, Basel, Switzerland. This article is an open access article distributed under the terms and conditions of the Creative Commons Attribution (CC BY) license (https:/ / creativecommons.org/licenses/by/ $4.0 /)$.

\begin{abstract}
Double Curved Concave Surface Sliders (DCCSS) are seismic isolators based on the pendulum principle widely used worldwide. Coherently with European code, DCCSS do not include any mechanical elements as end-stopper. In case of displacement higher than those associated with the design earthquakes, the inner slider runs on the edge of the sliding surfaces beyond their geometric displacement capacity keeping the ability to support gravity loads. In this paper, the advanced modelling and risk analysis of reinforced concrete (RC) base-isolated buildings designed for medium and high seismicity zones according to the Italian code has been assessed considering new construction and existing structures retrofitted using the seismic isolation technique. Pushover analyses and nonlinear dynamic analyses including inelastic superstructure behaviour and the over-stroke displacement of the isolation system have been carried out. Annual rates of failure are computed for Usability-Preventing Damage (UPD) related to the superstructure inter-storey drift and for Global Collapse (GC) associated with the ultimate displacement of the DCCSS. Moreover, the ultimate displacement is assumed with an extra-displacement of more than $30 \%$ of the maximum geometrical displacement. Results pointed out that in the case of new buildings the GC and UPD conditions occur almost at the same seismic intensity, while for the cases of the existing building, the UPD is the dominant limit state, being reached at an intensity level lower than GC.
\end{abstract}

Keywords: base isolation; double concave curved surface sliders; over-stroke displacement; nonlinear dynamic analysis; annual rates of failure

\section{Introduction}

Base isolation is one of the most used techniques for the seismic protection of buildings. Experience from past earthquakes, as well as numerical studies, highlights the seismic vulnerability of a large portion of the existing Reinforced Concrete buildings. Replacement of existing damaged buildings by reconstruction is generally avoided due to the high economic costs [1]. It has long been known that seismic isolation technology is one of the most effective solutions to protect new and existing buildings at both serviceability and ultimate limit states [2,3]. Correctly designed base-isolated buildings for design intensities earthquakes are not subjected to functionality loss and are immediately accessible in quakes aftermaths [4].

The isolated structures behaviour and the isolation system effectiveness have been widely investigated by several authors [5-10]. Recent research works have highlighted the main dependency of the frictional properties on some important response parameters, such as the sliding velocity, the recentering capacity, the contact pressure, the temperature rise during the sliding motion and the consequences of mounting laying defects for curved surface slider devices [11-15]. Precisely, it has been observed that the friction coefficient 
decreases as the contact pressure rises, due to fluctuations induced by either the vertical component of the seismic event or overturning effects, while the recentering capability depends only on the characteristics of the isolation system. In addition, the coefficient of friction should be also influenced by the temperature on the sliding interfaces. Moreover, differences in the effects of radial and bidirectional motions should be noticed.

Differently, studies and experimental investigations about isolated structures behaviour under collapse conditions and for high seismic intensities are limited [16-19]. In the recent past, some unexpected results have been returned by seismic risk assessment procedures applied to base-isolated structures. More specifically, previous studies [20] have shown a lower seismic risk level can be achieved for the "protected" structural system, equipped with an isolation layer, in comparison to a conventionally designed fixed-base configuration. Such results may be addressed to the initial definition of collapse for isolation devices, which generally are assumed to reach failure as soon as the maximum displacement from numerical simulations achieves the displacement capacity [18]. This assumption somehow considers the design displacement as a conservative quantity, which leads to lower uncertainties (apparently) in the response, and no extra capacity for the isolation system is taken into account [17]. On the other hand, structures with fixed-base configurations are generally designed considering safety factors, which increase external loads and decrease material strengths, so that a certain extra capacity can be achieved if the collapse limit state is analysed [21,22].

Experimental investigations on seismic isolation devices are conducted through testing protocols ruled by given standard codes, which aim at assessing the response of the isolators when subjected to the design displacement, and no further investigations are suggested for higher displacement demands. This aspect represents a very important issue to be investigated, especially when DCCSS devices are studied. Sliding-based isolators can be designed according to different technologies, depending on the common practice of the country. In particular, in Europe, most of the cases present the stainless-steel sliding surface either welded to the backing plate or installed within a recess with a consequent small counterbore gap. Some experimental tests have shown that stable force responses can be obtained, even if the geometrical displacement threshold is overcome [23-26]. On the other hand, in the United States, DCCSS devices can also be equipped with an external restraining rim, which limits the displacement demand within a certain upper bound, and consequently, a significantly increased value of base shear can be induced at the base of the building [27]. All these issues should be deeply analysed, both numerically and experimentally, to define the proper assumptions for a correct seismic risk assessment of base-isolated structural systems.

The RI-NTC (Implicit Risk of code-conforming Italian buildings) research project investigates the collapse and damage risk of code-designed structures in Italy and provides a probabilistic framework for the seismic risk estimation [20] incorporating both ground motion and system modelling uncertainties.

This paper describes research activities carried out on four case studies of six-storeys RC infilled frame base-isolated with an isolation system composed of DCCSS located in medium and high seismicity and designed according to the current Italian seismic code [28]. This study aims to identify critical aspects of the isolation system effectiveness in limiting building damage for high seismic intensities and to provide the basis for the implicit risk of damage assessment and global collapse considering the over-stroke displacement of DCCSS bearings. Two performance levels are defined: (i) the UsabilityPreventing Design (UPD), associated with the superstructure attainment of the global drift limit corresponding to the end of the elastic branch; (ii) the Global Collapse (GC) in which a DCCSS device reaches the over-stroke displacement limit. Non-Linear Time History Analyses (NTHAs) have been performed considering twenty bidirectional natural accelerograms for ten increasing seismic intensity levels characterised by return periods from 30 to 100,000 years. Numerical models accounting for the nonlinear behaviour of both the isolation system and the superstructure have been implemented. Results of newly 
designed and retrofitted isolated buildings are compared in terms of annual rates of failure for UPD and GC performance levels.

\section{Case studies}

\subsection{Archetype Buildings}

The prototype structure represents typical residential RC-frame buildings located in two different seismicity zones, according to the Italian national hazard map, and is characterised by a regular plan of approximately 240 square meters and 6 stories above ground. The ground level height is $3.4 \mathrm{~m}$ while the other stories heights are all $3.05 \mathrm{~m}$, the building includes a staircase, designed with knee beams, and all stories have the same $25 \mathrm{~cm}$-thick slab. Infill panels have been considered as regularly distributed in plan and elevation, with different opening percentages, infills dead loads have been considered in the design process. In the base-isolated configuration, a supplementary RC base slab has been implemented below the ground floor columns.

Four case studies of base-isolated buildings consisting of a new construction and two existing buildings located in the site of Naples and of L'Aquila (Italy) have been analysed in this study. The superstructure of the new building $[17,21]$ has been designed with the minimum spectral acceleration of $S_{e}=0.10 \mathrm{M}$, with $M$ being the seismic mass of the superstructure, and medium ductility class $\left(\mathrm{CD}^{\prime \prime} \mathrm{B}^{\prime \prime}\right)$ according to the Italian Seismic Code [28] prescriptions. Figure 1 shows a typical elevation and plan view of the new construction structure.

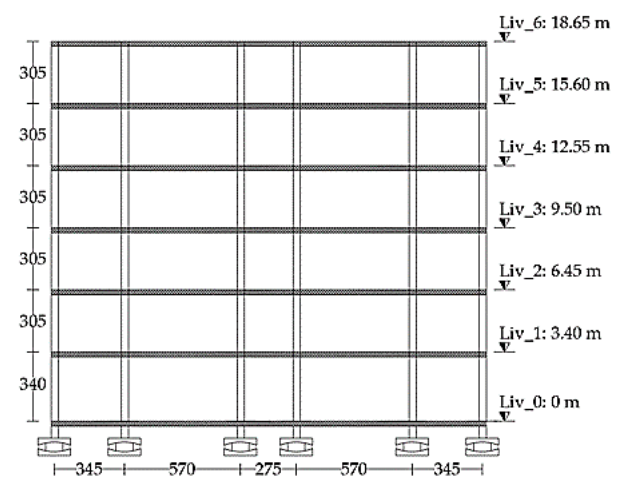

(a)

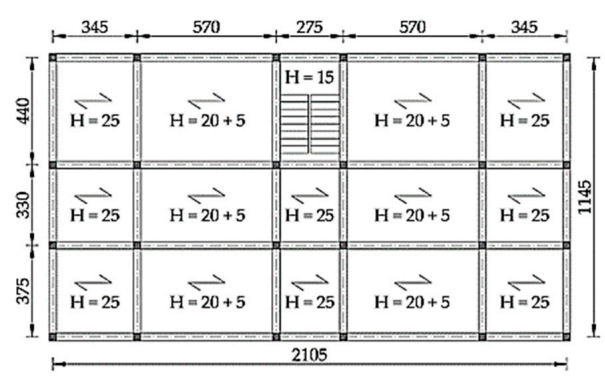

(b)

Figure 1. New construction isolated building: (a) side and (b) floor plan.

The existing buildings were designed with outdated seismic codes $[18,19,22]$ : the building located in Naples was designed for gravity loads only (GLD), according to D.M. 30/05/1974 [29]; the building located in L'Aquila was designed for low seismic loads (LSD) according to D.M. 24/01/1986 [30]. Floor plans are identical to the new one except for column and beam cross-section dimensions and reinforcement rebars according to the considered seismic codes. All of the perimetral beams are deeper than the slab, all internal beams are flat and they are in the y-direction only for the Naples building, and in both directions for the L'Aquila case. Figure 2 shows the floor plans of the existing structures for the (a) L'Aquila and (b) Naples sites. 


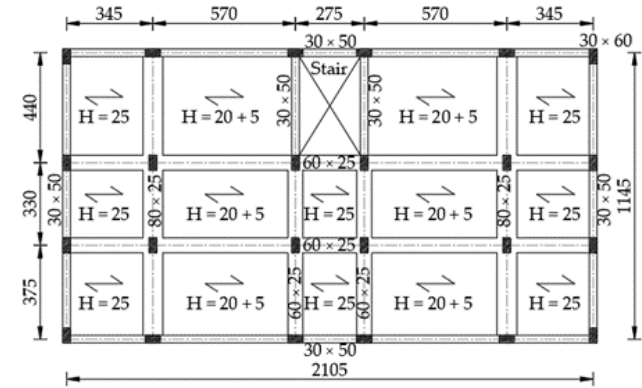

(a)

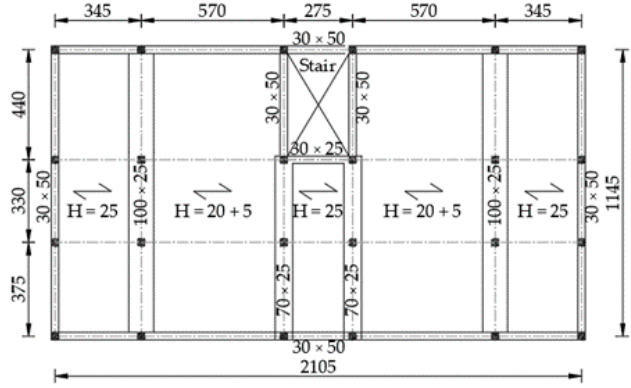

(b)

Figure 2. Plan views of existing buildings for the (a) L'Aquila and (b) Napoli.

Table 1 shows the seismic mass of the superstructure $M$ for all case studies. The seismic weight $W$ of the isolated buildings, which also includes the base slab mass, and the medium isolator axial load $N_{S d}$, evaluated considering the combination of seismic action with other gravity loads, are also reported in Table 1.

Table 1. Total mass and axial loads of archetype buildings.

\begin{tabular}{cccc}
\hline \multirow{2}{*}{ Case Study } & $\mathbf{M}$ & $\mathbf{W}$ & $\mathbf{N}_{\mathbf{S d}}$ \\
\cline { 2 - 4 } & [ton] & {$[\mathbf{k N}]$} & {$[\mathbf{k N}]$} \\
\hline New Construction & 2178 & 22,330 & 890 \\
Existing LSD & 1582 & 18,568 & 647 \\
Existing GLD & 1546 & 18,040 & 683 \\
\hline
\end{tabular}

\subsection{Seismic Input}

According to the Italian Seismic Code [28], the elastic response spectra of the selected case study structures are referred to design actions with return periods of 50 years (Damage Limit State DLS), 475 years (Life safety Limit State LLS) and 975 years (Collapse Limit State CLS) and to the soil type C. Reference to [20] can be made for further details about the seismic input.

This study aims to estimate the probability of reaching the collapse and usabilitypreventing performance levels supported by annual rates of failure computed by nonlinear dynamic analyses considering advanced modelling of the seismic isolation systems compared to that of previous studies $[17,18]$. The results of NTHAs, have been used to estimate the mean rates of failure $\lambda_{f}$ (using the R2R-EU software [31]) for both the GC and UPD performance levels implementing the Performance-based Earthquake Engineering Framework [32].

Multi-stripe non-linear dynamic analyses have been carried out considering 20 ground motions per 10 intensity measure levels (IMs), as reported Table 2.; IM2, IM5, and IM6 correspond to the return periods of the DLS, LLS, and CLS. Due to base-isolated structures vibration period, generally assumed as $\mathrm{T}=3 \mathrm{sec}$ for this kind of isolation system, the attenuation law of Akkar and Bommer [33] has been implemented to compute hazard and disaggregation. The elastic spectra of seismic inputs for IM6, as an example compared with design spectra provided by code for CLS, are reported in Figure $3 \mathrm{a}, \mathrm{b}$ for the sites of L'Aquila and Naples, respectively. 
Table 2. Spectral acceleration $\mathrm{Sa}(\mathrm{T}=3 \mathrm{~s})$ expressed in $[\mathrm{g}]$ for the IMs.

\begin{tabular}{|c|c|c|c|c|c|c|c|c|c|c|}
\hline IM & 1 & 2 & 3 & 4 & 5 & 6 & 7 & 8 & 9 & 10 \\
\hline $\mathrm{T}_{\mathrm{R}}$ (Years) & 10 & 50 & 100 & 250 & 500 & 1000 & 2500 & 5000 & 10,000 & 100,000 \\
\hline $\begin{array}{c}\mathrm{L}^{\prime} \text { Aquila, } \mathrm{S}_{\mathrm{a}} \\
(\mathrm{T}=3 \mathrm{~s})\end{array}$ & 0.0002 & 0.011 & 0.031 & 0.062 & 0.11 & 0.177 & 0.271 & 0.384 & 0.576 & 1.053 \\
\hline $\begin{array}{l}\text { Naples, } S_{a} \\
(T=3 s)\end{array}$ & 0.001 & 0.009 & 0.026 & 0.044 & 0.067 & 0.093 & 0.126 & 0.162 & 0.216 & 0.348 \\
\hline
\end{tabular}

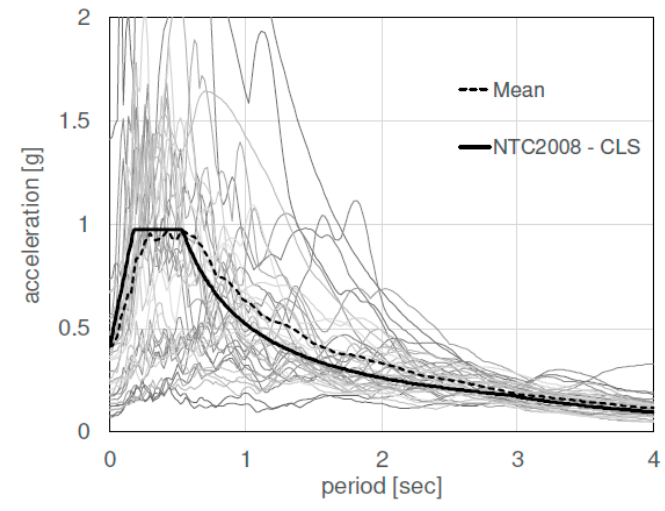

(a)

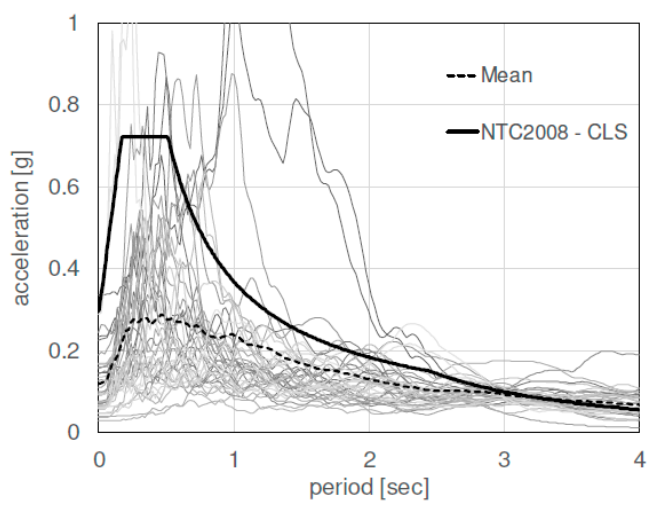

(b)

Figure 3. Response spectrum of ground motion for IM 6 (CLS $-T_{R}=1000$ years) - site of L'Aquila (a) and site of Napoli (b).

\subsection{Design of Isolation Systems}

The design displacement $\mathrm{d}_{\mathrm{Ed}}$ of the isolation systems has been estimated referring to the simplified linear analysis method considering the horizontal dynamic translation of DCCSS bearings (Figure 4a), without superimposing static torsional effect, and assuming the superstructure as a rigid body. Referring to Figure $4 \mathrm{~b}$ ), the main parameters of the linear equivalent model of the isolation system based on DCCSS bearings are effective stiffness $K_{e}$, effective period $T_{e}$ and effective damping $\xi_{e}$ as reported in Equation (1), where $R_{e}$ is the effective radius, $\mu$ is the friction coefficient, $g$ is the gravity acceleration. The friction pendulum forces are proportional to the device axial load and the sliding velocity.

$$
\mathrm{K}_{\mathrm{e}}=\mathrm{N}_{\mathrm{Sd}}\left(\frac{1}{\mathrm{R}_{\mathrm{e}}}+\frac{\mu}{\mathrm{d}_{\mathrm{Ed}}}\right), \mathrm{T}_{\mathrm{e}}=\pi \sqrt{\frac{1}{\mathrm{~g}\left(\frac{1}{\mathrm{R}_{\mathrm{e}}}+\frac{\mu}{\mathrm{d}_{\mathrm{Ed}}}\right)}}, \xi_{\mathrm{e}}=\frac{2}{\pi} \cdot \frac{1}{\frac{\mathrm{d}_{\mathrm{Ed}}}{\mu \cdot \mathrm{R}_{\mathrm{e}}}+1},
$$

The design procedure for the new construction case studies for L'Aquila (AQ_new) and Naples (NA_new) sites is shown in Figure 5, in terms of Acceleration-Displacement Response Spectra (ADRS). The design displacement $\mathrm{d}_{\mathrm{Ed}}$ at the CLS and the characteristics of designed DCCSS bearings are summed up Figure 5.

The design procedure of the isolation system for existing building case studies starts from the spectral acceleration associated with the occurrence of the first plastic hinge $\left(\mathrm{S}_{\mathrm{e}, \min }=\mathrm{V}_{\mathrm{e}} / \mathrm{M}\right)$. The elastic limit of the base shear $\mathrm{V}_{\mathrm{e}}$ of the superstructure in the fixedbase configuration has been identified from pushover curves (as described later). To take into account the structural uncertainties, the aforesaid spectral acceleration has been divided by a safety factor equal to 1.1 , the design acceleration at the LLS is $S_{\mathrm{e}}^{*}=\mathrm{S}_{\mathrm{e}, \mathrm{min}} / 1.1$ as shown in Figure 6 (red dashed lines). The minimum value of the fundamental period $\mathrm{T}_{\mathrm{iso} \text {,min }}$ of the base-isolated system is then found. The design procedure for the existing case studies (AQ_LSD; NA_GLD) is shown in Figure 6. 


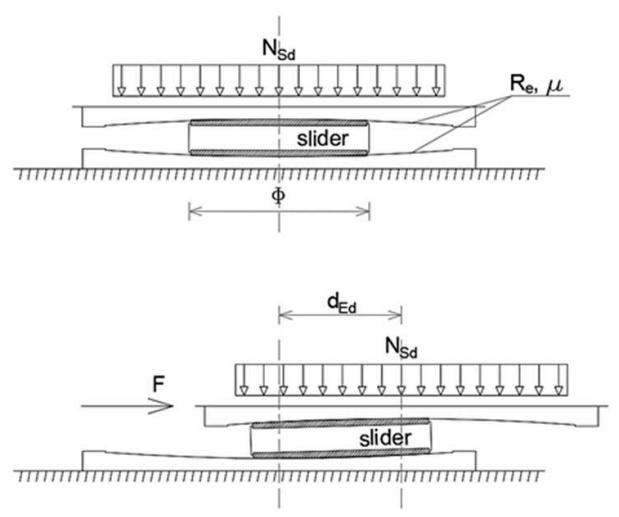

(a)

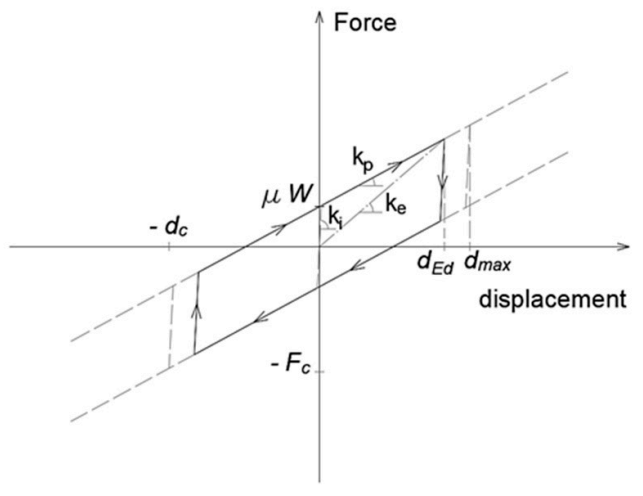

(b)

Figure 4. (a) DCCSS bearing and (b) linear equivalent model.

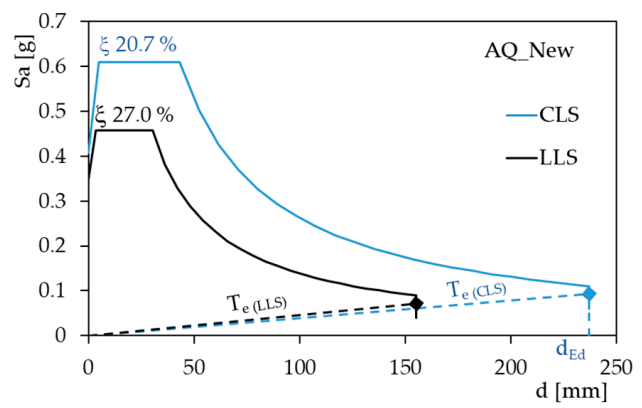

(a)

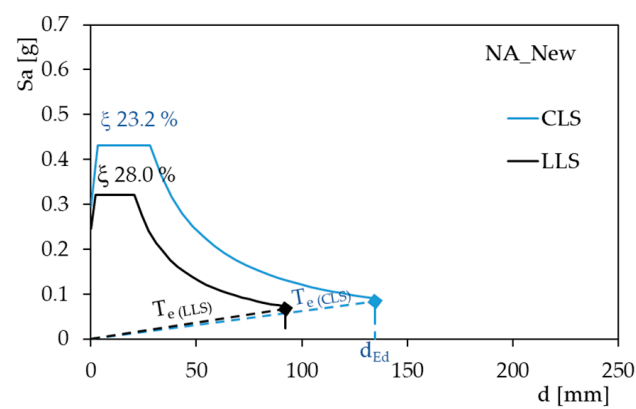

(b)

Figure 5. Isolation system design procedure on CLS and LLS spectra for the cases of New construction building in the site of L'Aquila (a) and Naples (b).

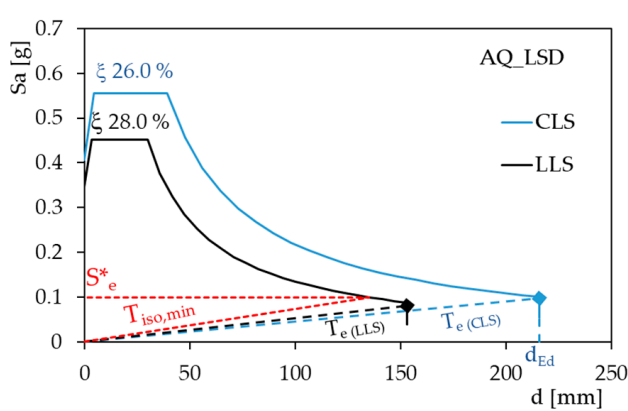

(a)

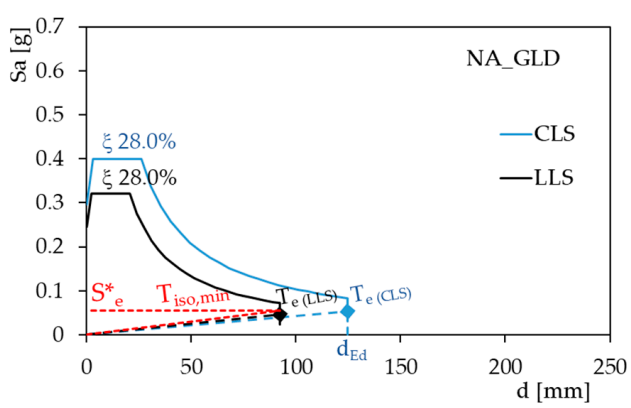

(b)

Figure 6. Elastic limits from pushover curves of existing buildings and isolation system design procedure for the cases of L'Aquila (a) and Naples (b).

The characteristics of designed DCCSS bearings for all case studies are reported in Table 3. The maximum displacement $\mathrm{d}_{\max }$ has been assumed by catalogue, taking into account torsional effects. 
Table 3. Geometric characteristics and main design parameters of the isolation system at the CLS.

\begin{tabular}{ccccccccc}
\hline \multirow{2}{*}{$\begin{array}{c}\text { Case } \\
\text { Study }\end{array}$} & $\mathbf{R}_{\mathbf{e}}$ & $\boldsymbol{\mu}$ & $\mathbf{K}_{\mathbf{e}}$ & $\mathbf{T}_{\mathbf{e}}$ & $\boldsymbol{\xi}_{\mathbf{e}}$ & $\mathbf{d}_{\mathbf{E d}}$ & $\boldsymbol{\Phi}$ & $\mathbf{d}_{\mathbf{m a x}}$ \\
\cline { 2 - 9 } & {$[\mathbf{m m}]$} & {$[\%]$} & {$[\mathbf{k N} / \mathbf{m m}]$} & {$[\mathbf{s e c}]$} & {$[\%]$} & {$[\mathbf{m m}]$} & {$[\mathbf{m m}]$} & {$[\mathbf{m m}]$} \\
\hline AQ_New & 3700 & 2.5 & 0.357 & 3.17 & 21 & 237 & 200 & \pm 300 \\
NA_New & 2500 & 2.5 & 0.560 & 2.53 & 23 & 134 & 250 & \pm 150 \\
AQ_LSD & 3700 & 2.5 & 0.296 & 2.97 & 26 & 216 & 200 & \pm 300 \\
NA_GLD & 4500 & 2.5 & 0.303 & 3.01 & 28 & 125 & 165 & \pm 250 \\
\hline
\end{tabular}

\section{Numerical Modelling}

Nonlinear models have been developed in OpenSEES [34], including the superstructure (Figure 7a) and the isolation system with over-stroke capacity (Figure 7b,c). To correctly predict the effects of the superstructural inelastic behaviour on the seismic response of base-isolated buildings, a lumped plasticity model has been implemented for the main elements of the superstructures. The flexural behaviour of the plastic hinges for beams and columns critical cross-sections, considering axial load interaction effects, has been assumed with the Ibarra-Medina-Krawinkler [35] model. The model includes staircase knee beams and cantilever steps modelled as non-linear elements.

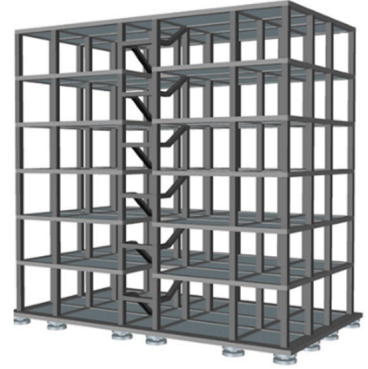

(a)

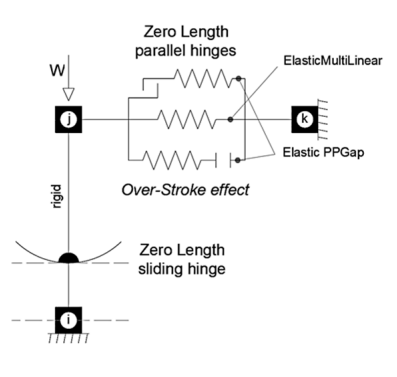

(b)

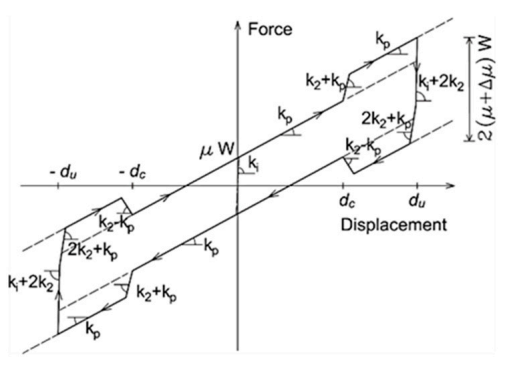

(c)

Figure 7. (a) Schematical representation of the base-isolated prototype building. DCCSS isolators: (b) numerical models and (c) constitutive law.

To take into account and model the possible onset of non-ductile failure modes in elements expected to experience a shear failure, prior to or following flexural yielding, such as staircase short columns structural members, the ultimate rotation capacity of plastic hinges has been defined through empirical models providing the expected deformation capacity at shear and axial failures [21,22]. A modified version of the Decanini model [36] has been used for masonry infill panels modelled with an equivalent compression-only strut considering a proper reduction of strength and lateral stiffness due to openings influence and potential premature out-of-plane collapse. In this study, 5\% Rayleigh damping is used to model the viscous damping of the superstructure. Previous studies have shown that this approach could result in fictitiously large damping forces in base-isolated buildings resulting in underestimation of the first-mode and higher mode responses. Future studies focusing on the topic of the present manuscript should also consider alternative approaches proposed in the literature for modelling the viscous damping of the superstructure [37-39]. Reference to $[17-19,21,22]$ can be made for further modelling details.

The finite element friction-pendulum isolator (SingleFPBearing) was used for the DCCSS isolator modelling in numerical nonlinear analyses. The cyclic nonlinear behaviour shows an initial stiffness $K_{i}$ before sliding, with a quasi-rigid behaviour, and a restoring stiffness $K_{p}=N / R_{e}$, as shown in Figure 7c). As generally supposed by manufacturers, the isolation devices maximum geometric capacity displacement is $\mathrm{d}_{\mathrm{c}}=\mathrm{d}_{\max } \cdot 1.1$ as shown in Figure 8a). The velocity dependence of the friction coefficient $\mu$ is modelled as described in [37]. High values for initial and vertical stiffness have been used $\left(K_{i}=5.0 \mathrm{kN} / \mathrm{mm} ; K_{V}=1.5 \mathrm{e} 6 \mathrm{kN} / \mathrm{mm}\right)$. In the present work, the dependency of the friction coefficient on the applied contact pressure 
and the temperature rise has been neglected, to better highlight the direct consequences of the over-stroke response.

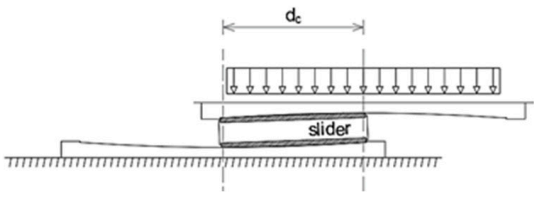

(a)

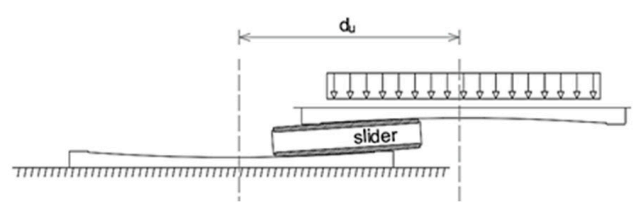

(b)

Figure 8. Maximum geometric (a) and ultimate (b) displacement of DCCSS Isolators.

When the inner slider runs across the flat rim of the housing plate beyond the geometric capacity displacement $d_{c}$, it enters the over-stroke sliding regime as shown in Figure $8 b$ ). This state of motion is characterised by increases in stiffness $K_{2}$ and friction coefficient $\Delta \mu$ with a typical "sloping dog bone" shape behaviour shown in Figure 7c).

In the over-stroke sliding regime, the collapse condition is reached when the vertical load support is no more granted due to the inner slider instability. The vertical instability is generally attained when the displacement demand exceeds an ultimate displacement $d_{u}$ equal to the geometric capacity $d_{c}$ increased of half diameter of the inner slider $\Phi(25 \%$ for the upper plate and $25 \%$ for the lower plate) preserving the ability to support gravity loads, see Equation (2).

$$
\mathrm{d}_{\mathrm{u}}=\mathrm{d}_{\mathrm{c}}+1 / 2 \cdot \Phi
$$

To properly represents the isolators over-stroke displacement, the basic OpenSEES model (SingleFPBearing) has been modified by adding three zero-length parallel hinges from j-node to k-node of Figure 7b). The numerical model calibration of DCCSS over-stroke displacement has been carried out with reference to experimental characterization tests performed on similar bearings $[18,24,40,41]$, the main parameters of the numerical model are reported in Table 4.

Table 4. Over-stroke parameters of the isolation system.

\begin{tabular}{cccccc}
\hline & $\mathbf{d}_{\mathbf{c}}$ & $\mathbf{d}_{\mathbf{u}}$ & $\mathbf{K}_{\mathbf{p}}$ & $\mathbf{K}_{\mathbf{2}}$ & $\Delta \boldsymbol{\mu}$ \\
\cline { 2 - 6 } Case_ID & {$[\mathbf{m m}]$} & {$[\mathbf{m m}]$} & {$[\mathbf{k N} / \mathbf{m m}]$} & {$[\mathbf{k N} / \mathbf{m m}]$} & - \\
\hline AQ_New & \pm 330 & 430 & 0.240 & 2.50 & 0.02 \\
NA_New & \pm 165 & 290 & 0.172 & 2.50 & 0.02 \\
AQ_LSD & \pm 330 & 430 & 0.174 & 2.50 & 0.02 \\
NA_GLD & \pm 275 & 355 & 0.372 & 2.50 & 0.02 \\
\hline
\end{tabular}

\section{Definition of Performance Levels}

The engineering demand parameters (EDP) defined to control the seismic performance of isolated buildings are the superstructure global drift and the isolation system displacement for the attainment of the Limit State corresponding to the Usability-Preventing Design (UPD) and the Global Collapse (GC), respectively.

The UPD is defined as the performance level in which the structure, with its structural and nonstructural elements, undergoes a damage level that does not expose its occupants to any risk and does not compromise the strength and stiffness of the structural elements; the structure is immediately accessible even if some equipment is not fully operational. A multi-criteria approach has been adopted to define the limit value of drift $d r i f t_{l i m}$ for UPD level combining conditions related to easy non-structural components reparability and no service interruption with the conditions of protecting structural members from damage for frequent earthquakes [42]. The UPD failure condition is attained when the superstructure global drift corresponding to the end of the elastic branch on pushover curves is reached. Figure 9 sums up the threshold values of the top displacements found on the pushover curves for the case studies carried out on the fixed-based superstructures, with a force 
distribution proportional to the storey masses using a barycentric node in the top floor as control node $[20,21,43]$.

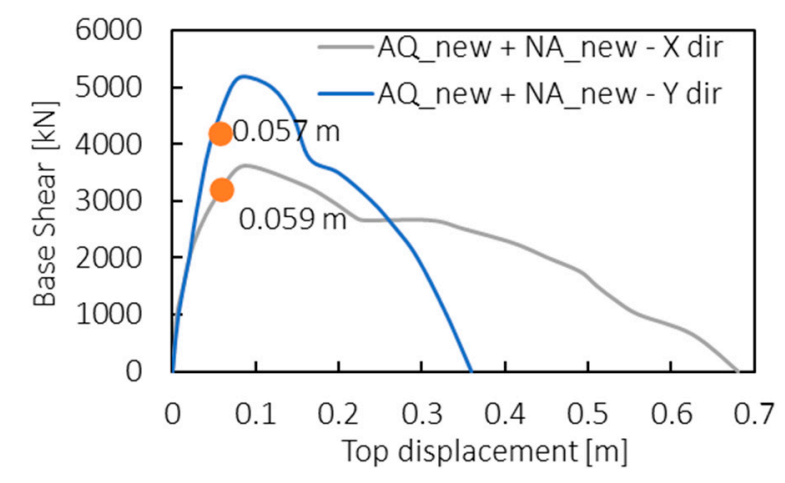

(a)

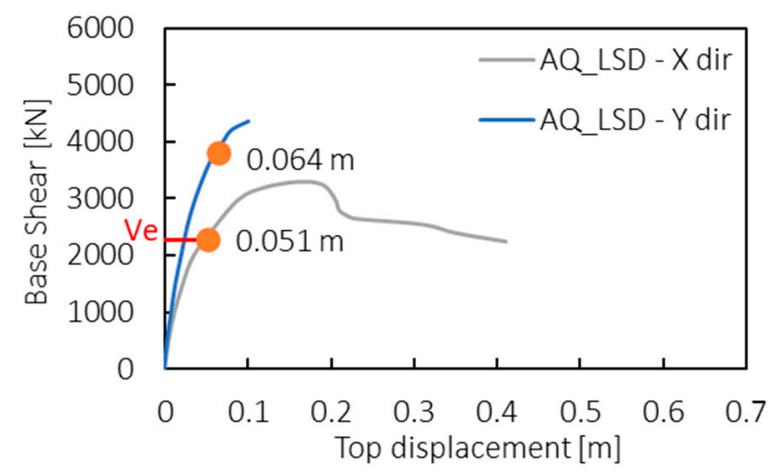

(b)

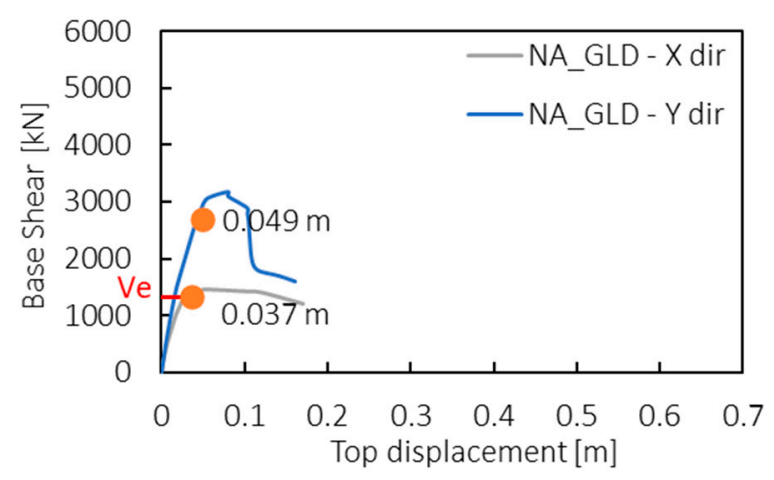

(c)

Figure 9. Limit values of top displacement associated with the attainment of the Usability-preventing Performance Level, as derived from Pushover analysis for new construction buildings (a), and existent buildings in the sites of L'Aquila (b) and Naples (c).

The GC is defined as the performance level in which one DCCSS device reaches the limit displacement $d_{\text {lim }}$ in the over-stroke regime, mainly dependent on the contact pressure and sliding material degradation. It has been observed that the limit displacement $\mathrm{d}_{\text {lim }}$ is related to the contact pressure supported by the sliding material and to the number of cycles over in the over-stroke regime. The area of contact between the plates surfaces and the inner slider reduces and a peak in contact pressure can be reached. When the inner slider runs on the edge of the sliding surfaces the friction coefficient increases and the sliding material suffers some damage. For the case studies, a Polytetrafluoroethylene (PTFE)-based sliding material with a maximum contact pressure of $60 \mathrm{MPa}$ has been assumed and a number of two over-stroke cycles has been allowed. Depending on the thickness of the inner slider, the covered area at the sliding interfaces or the overlapped area 
between the backing plates can be considered for the computation of the average contact pressure: if the thickness is enough to ensure a proper vertical stress distribution the former can be adopted, otherwise the latter represents a more correct parameter. Figure 10 shows the ratio between the limit displacement $d_{\text {lim }}$ and maximum capacity displacement $d_{c}$ corresponding to the maximum contact pressure on the covered area of the slider for each case study. For three case studies (AQ_new, AQ_LSD and NA_GLD) the contact pressure limit is reached before the ultimate displacement $d_{u}$. All failure conditions and limit values are summarised in Table 5 .

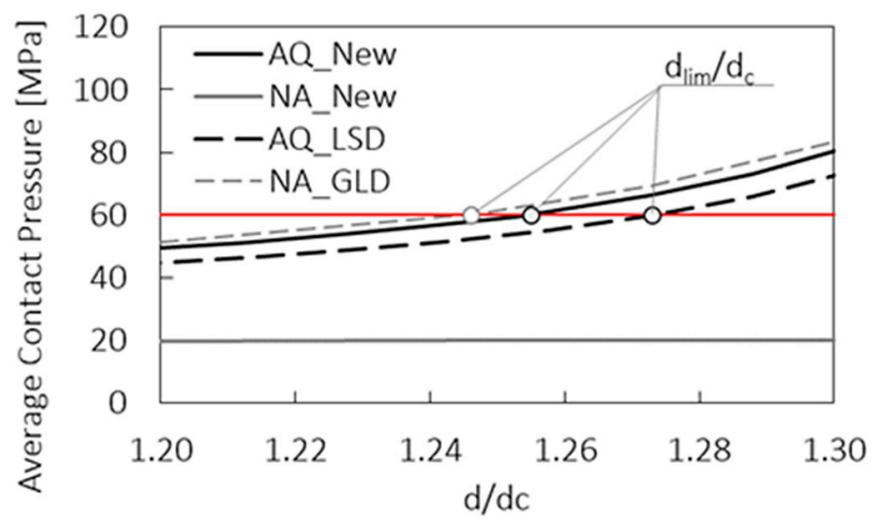

Figure 10. Limit displacement function of the contact pressure of DCCSS sliding material for the GC performance level.

Table 5. Definition of the performance levels for the isolated buildings.

\begin{tabular}{|c|c|c|c|c|}
\hline Limit State & EDP & Failure Conditions & Case ID & Limit Value \\
\hline UPD & Superstructure global drift ${ }_{\text {lim }}$ & $\begin{array}{c}\text { End of the elastic branch on } \\
\text { pushover curves for } \\
\text { directions } X \text { and } Y\end{array}$ & $\begin{array}{l}\text { AQ_New } \\
\text { NA_New } \\
\text { AQ_LSD } \\
\text { NA_GLD }\end{array}$ & $\begin{array}{l}0.32 \% ; 0.31 \% \\
0.32 \% ; 0.31 \% \\
0.27 \% ; 0.34 \% \\
0.20 \% ; 0.26 \%\end{array}$ \\
\hline GC & Maximum displacement of isolators $\mathrm{d}_{\mathrm{lim}}$ & $\begin{array}{l}\text { Vertical instability or contact } \\
\text { pressure of the } \\
\text { sliding material }\end{array}$ & $\begin{array}{l}\text { AQ_New } \\
\text { NA_New } \\
\text { AQ_LSD } \\
\text { NA_GLD }\end{array}$ & $\begin{array}{l}414 \mathrm{~mm} \\
290 \mathrm{~mm} \\
420 \mathrm{~mm} \\
342 \mathrm{~mm}\end{array}$ \\
\hline
\end{tabular}

\section{NTHA Results}

Nonlinear Time History Analyses were performed by considering a set of 200 ground motions, consisting of 20 records for each intensity measure level (IM), as reported in Table 2. The GC limit is explained in Figure 11 where an example of force vs. displacement behaviour and displacement orbit of the corner DCCSS device at IM6 (Earthquake number 2) for the case of the existing isolated building located in L'Aquila is reported, together with the ultimate displacement (orange continuous line) and the displacement capacity (orange dashed line). As can be observed from Figure 11a) the numerical model well describes the over-stroke displacement. The collapse of the DCCSS is attained when isolators displacement $\mathrm{d}>\mathrm{d}_{\text {lim }}$, as shown in Figure 11b). 


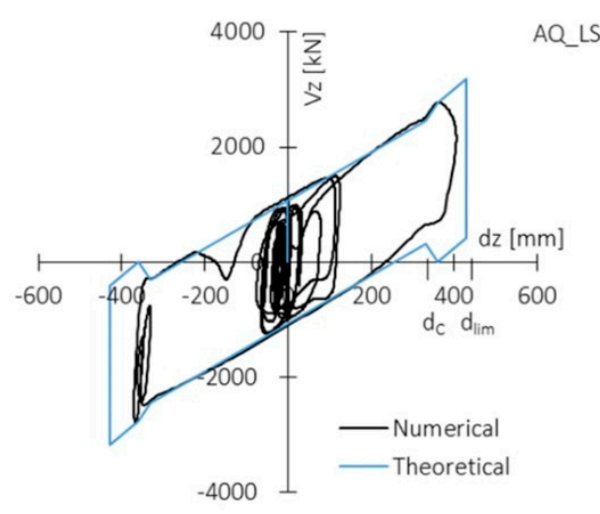

(a)

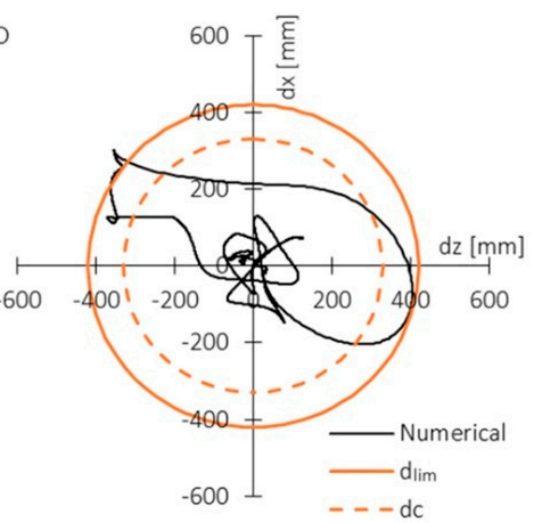

(b)

Figure 11. Results for an LLS (IM 6; EQ no. 2) intensity accelerogram on a force vs displacement diagram (a) and in plan view (b).

Figure 12 shows the results about the GC performance level in terms of the number of records vs. IM for which the EDP limit is attained. Results show the AQ_New case study is characterised by the highest number of failures. Furthermore, for the cases located in the site of L'Aquila, the isolation system failure is attained for seismic intensities close to the design one (IM6-CLS), while for Naples cases, this condition is only reached for high seismic intensities.
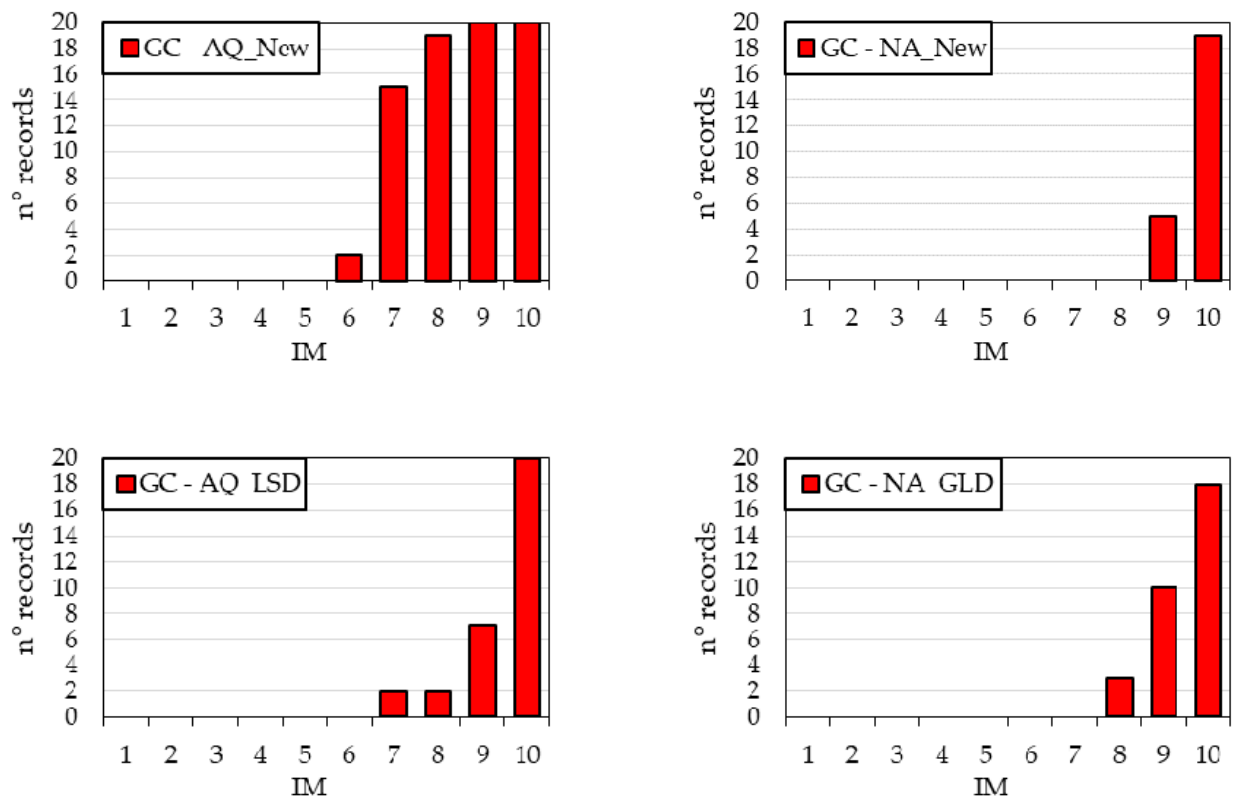

Figure 12. GC results for the four case studies analysed.

The results in terms of UPD performance level are reported in Figures 13-16 in terms of $\mathrm{D} / \mathrm{C}$ ratios vs IM. The total number of failure cases $(\mathrm{D} / \mathrm{C} \geq 1$ ) is shown on top of the charts, red dots represent the superstructural UPD failure cases, while the cases in which isolation system failure (GC) is registered are represented with a blank dot, for these records the UPD performance level is considered attained too, regardless of the $\mathrm{D} / \mathrm{C}$ ratio. As can be seen, in accordance with the GC results, a significant number of failures is only registered for intensities higher than the IM6 for the site of L'Aquila. For the NA_New case, the EDP limit is attained for IM10 only, this effect is due to the updated superstructure design and the lower seismic hazard of the site. Moreover, an average value of 0.2 for the D/C ratio is recorded at IM2 (DLS) for both the New construction buildings, 
see Figures 13 and 14, while, for the existing buildings a higher average value of the D/C ratio is attained for the same intensity measure, see Figures 15 and 16, proving the effect of the major superstructure deformability.

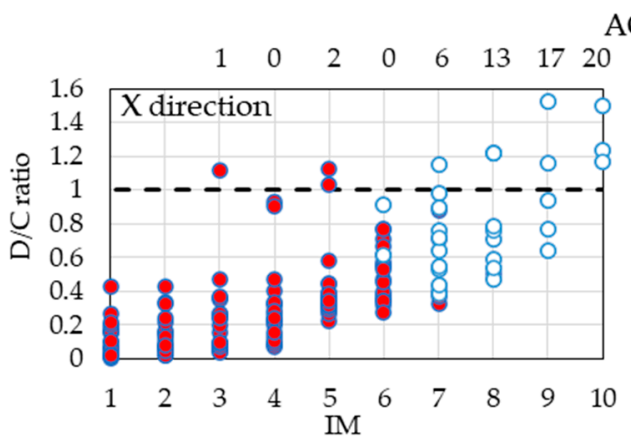

(a)
AQ_New

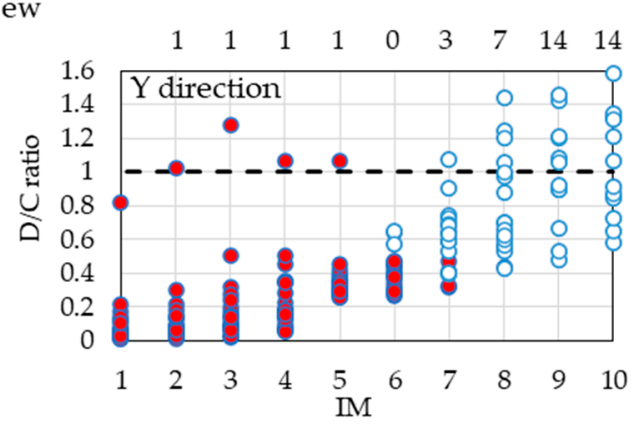

(b)

Figure 13. Displacement D/C ratios of the superstructure (UPD): AQ_New $X(\mathbf{a})$ and $Y(\mathbf{b})$ directions.

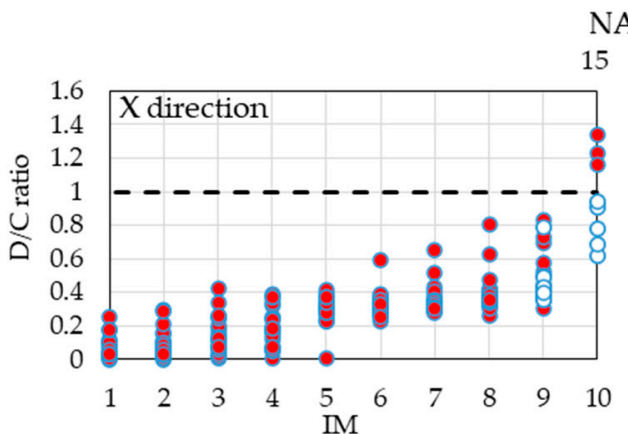

(a)

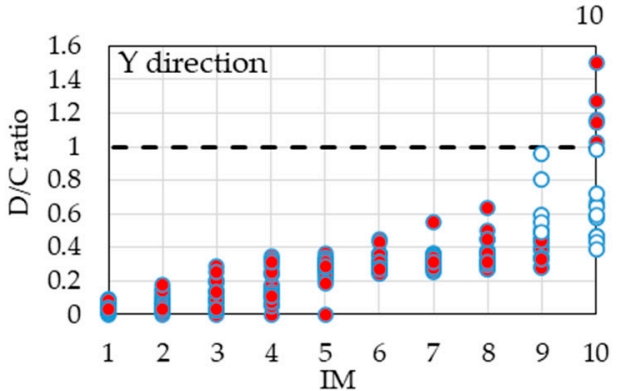

(b)

Figure 14. Displacement D/C ratios of the superstructure (UPD): NA_New $X(\mathbf{a})$ and $Y(\mathbf{b})$ directions.

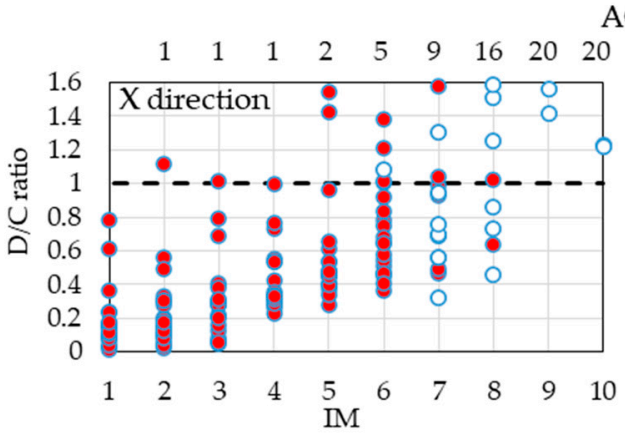

(a)

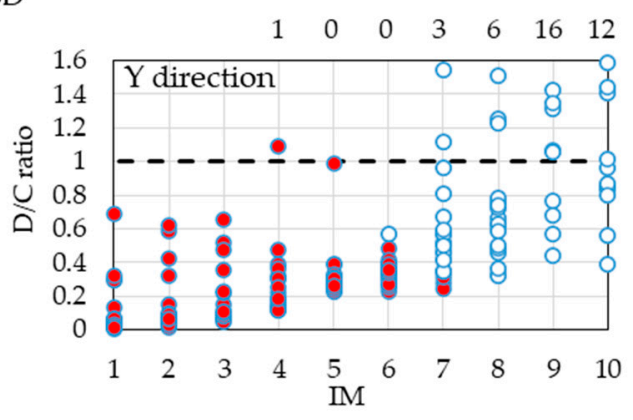

(b)

Figure 15. Displacement D/C ratios of the superstructure (UPD): AQ_LSD X (a) and Y (b) directions. 


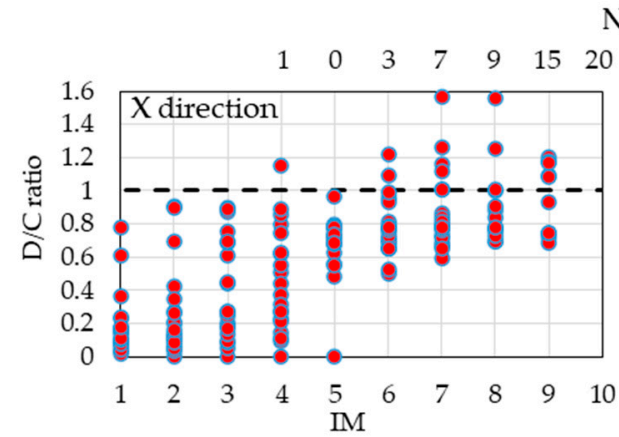

(a)
NA_GLD

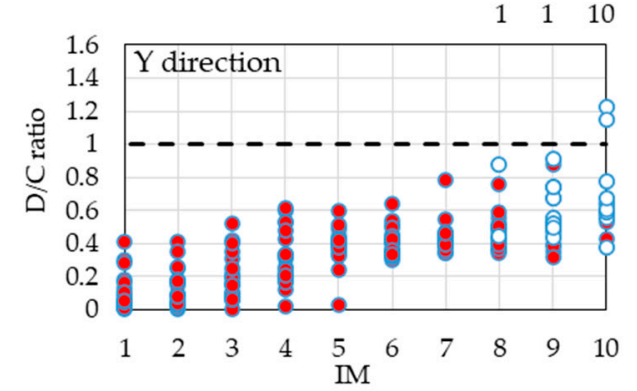

(b)

Figure 16. Displacement D/C ratios of the superstructure (UPD): NA_GLD X (a) and Y (b) directions.

\section{Risk Assessment}

The results of seismic risk assessment are presented in terms of mean Annual Rates of Failure of UPD leading the superstructure to the drift limit and GC reaching the limit displacement of DCCSS isolators. Figure 17 shows the comparison of the mean annual rates evaluated for all the case studies for the GC (a) and the UPD (b) performance levels, to provide a prediction of potential damage during an earthquake higher than the CLS (corresponding to IM6) for the base-isolated models. The UPD rates confirm that seismic isolation works effectively in limiting damage to non-structural components for seismic intensities much higher than the design earthquake intensity level DLS (corresponding to IM2). Dashed horizontal lines highlight the reference probabilities of exceedance provided by the Italian seismic code NTC18 [28], i.e., $1.00 \times 10^{-3}$ for GC and $1.26 \times 10^{-2}$ for UPD. Due to the advanced model with the extra displacement capacity gained in the over-stroke regime, for the new base-isolated building the GC rates associated with the attainment of the DCCSS limit displacement appear almost identical to UPD ones. For the retrofitted base-isolated building the superstructure failure becomes more significant, UPD rates are linked to higher probabilities of exceeding than the GC ones, mainly due to the higher deformability of the superstructure.

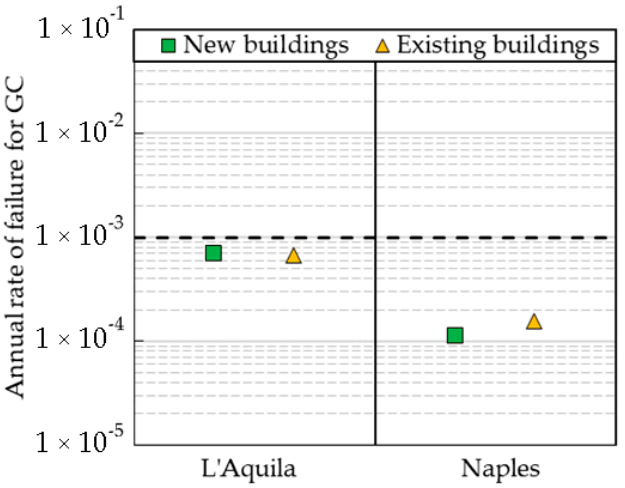

(a)

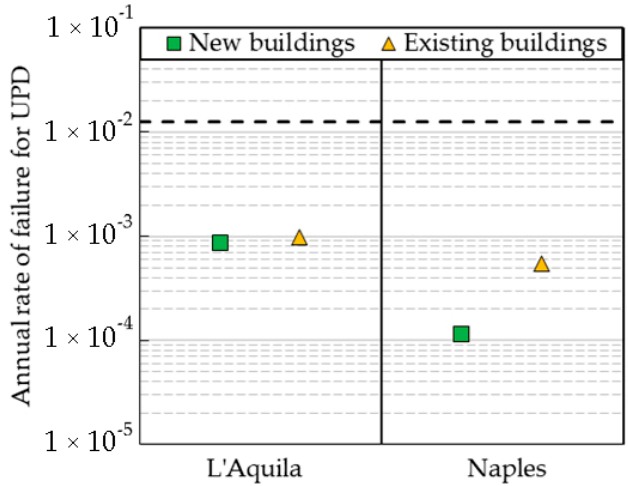

(b)

Figure 17. Annual rates of failure for the analysed base-isolated case studies, for the GC (a) and the UPD (b) performance levels.

The values of the annual rates of failure derived at UPD and GC limit states for the examined case studies are reported in Table 6 and compared to the results showed in the aforementioned works. Assuming an extra-displacement of more than $30 \%$ of the maximum geometrical displacement, few differences between UPD and GC can be observed and the rates are about the same values in both cases of new constructions isolated buildings and the case of structure designed with low seismic design retrofitted for high 
seismicity zone (site of L'Aquila). In the case of the existing building designed for gravity load only and retrofitted for medium seismicity zone (site of Naples), the difference between the UPD and GC rates increased; in this case, the over-stroke displacement contribution is negligible.

Table 6. Annual rates of failure for the analysed cases.

\begin{tabular}{ccc}
\hline Case_ID & Limit State & Annual Rate of Failure $\lambda_{\mathbf{f}}$ \\
\hline \multirow{2}{*}{ AQ_New } & UPD & $8.7 \times 10^{-4}$ \\
& GC & $7.0 \times 10^{-4}$ \\
\hline \multirow{2}{*}{ NA_New } & UPD & $1.1 \times 10^{-4}$ \\
& GC & $1.1 \times 10^{-4}$ \\
\hline \multirow{2}{*}{ AQ_LSD } & UPD & $9.8 \times 10^{-4}$ \\
& GC & $6.6 \times 10^{-4}$ \\
\hline \multirow{2}{*}{ NA_GLD } & UPD & $5.4 \times 10^{-4}$ \\
& GC & $1.5 \times 10^{-4}$ \\
\hline
\end{tabular}

\section{Conclusions}

This paper presents the results of an ongoing RINTC research project investigating the global collapse (GC) and the usability preventing damage (UPD) limit states of reinforced concrete (RC) buildings with isolation systems based on double concave curved surface sliders (DCCSS). Starting from the same 6-storey prototype building, four case studies of isolation systems have been designed considering two different sites, characterised by medium and high seismicity, and including two existing structures retrofitted through the base isolation technique.

Bi-directional nonlinear dynamic analyses considering twenty natural earthquakes for ten increasing seismic intensity levels have been carried out. The numerical model includes the nonlinear behaviour of the superstructure elements and the infill panels considered as drift-sensitive non-structural components. An advanced non-linear model of the DCCSS over-stroke capacity calibrated with specific experimental tests conducted on similar bearings is adopted. The model can describe the DCCSS behaviour when the displacement exceeds the maximum geometric capacity and a limit associated with the loss of vertical support due to overturning mechanisms of the inner slider is reached. The influence of the contact pressure on the sliding material degradation has been considered for the estimation of the limit displacement of DCCSS bearings. High values of contact pressure in the sliding material, due to the decreasing contact area between the housing plates and the slider, reduce the ultimate over-stroke displacement of the bearing.

Results show the isolation systems efficiency in limiting non-structural damage for seismic intensities even higher than the design one and also point out their little margin toward collapse for these intensity levels. In cases of retrofitted buildings, the superstructure failure has shown to be the main failure mode, especially for the case of the building designed without seismic rules due to the deformability of the structure. Differently, the isolation system collapse is always the prevalent failure mode for new base-isolated buildings mainly due to the generally low design margin of isolation devices. The influence of different procedures assumed for the design of seismic isolators for new and existing buildings is negligible. Compared with the results obtained in previous works considering the unlimited elasto-plastic behaviour modelling of isolation systems, the probability of reaching the GC limit state reduces to values comparable with the UPD limit state when over-stroke capacity is considered.

Further research should be carried out on the topic, from a two-fold point of view: many other case study structures need to be numerically investigated, to generalise the drawn conclusions also considering the responses of acceleration-sensitive non-structural components and building contents; additional experimental testing campaigns should be performed to evaluate possible dependencies of the over-stroke effect of DCCSS devices 
on some response parameters, such as vertical load and sliding velocity, or the number of subsequent cycles which can be run without significant cumulative damage.

Author Contributions: Conceptualization, A.D.C., F.C.P. and A.P.; methodology, A.D.C. and A.T.; numerical analysis, M.F. and A.T.; data processing, A.T. and M.F.; project administration, F.C.P. and A.P.; writing original draft, A.T. and M.F.; writing review and editing, A.D.C. All authors have read and agreed to the published version of the manuscript.

Funding: This study was funded by the Italian Civil Protection Department.

Institutional Review Board Statement: Not applicable.

Informed Consent Statement: Not applicable.

Data Availability Statement: The data presented in this study are available on request from the corresponding author.

Acknowledgments: The authors would like to acknowledge the ReLUIS Consortium (http:/ / www. reluis.it/ (accessed on 20 February 2021)), this research is developed within the ReLUIS Project 2019/21-Work Packages no. 3 and 15.

Conflicts of Interest: The authors declare no conflict of interest.

\section{References}

1. Di Cesare, A.; Ponzo, F.C.; Vona, M.; Dolce, M.; Masi, A.; Gallipoli, M.R.; Mucciarelli, M. Identification of the Structural Model and Analysis of the Global Seismic Behaviour of a RC Damaged Building. SDEE 2014, 65, 131-141. [CrossRef]

2. Kawamura, S.; Sugisaki, R.; Ogura, K.; Maezawa, S.; Tanaka, S.; Yajima, A. Seismic isolation retrofit in Japan. In Proceedings of the 12th WCEE, Auckland, New Zealand, 30 January-4 February 2000.

3. Mokha, A.S.; Amin, N.; Constantinou, M.C.; Zayas, V. Seismic isolation retrofit of large historic building. JSE 1996, 122, 298-308. [CrossRef]

4. Pant, D.R.; Wijeyewickrema, A.C. Performance of base-isolated reinforced concrete buildings under bidirectional seismic excitation considering pounding with retaining walls including friction effects. EESD 2014, 43, 1521-1541. [CrossRef]

5. Morita, K.; Takayama, M. Behavior of seismically isolated buildings during the 2016 Kumamoto earthquakes. In Proceedings of the NZSEE Conference 2017, Wellington, New Zealand, 27-29 April 2017.

6. Kazantzi, A.K.; Vamvatsikos, D. Practical performance-based design of friction pendulum bearings for a seismically isolated steel top story spanning two RC towers. Bull. Earthq. Eng. 2020, 19, 1231-1248. [CrossRef]

7. Takaoka, E.; Takenaka, Y.; Nimura, A. Shaking table test and analysis method on ultimate behavior of slender base-isolated structure supported by laminated rubber bearings. EESD 2011, 40, 551-570. [CrossRef]

8. De Domenico, D.; Gandelli, E.; Quaglini, V. Effective base isolation combining low-friction curved surface sliders and hysteretic gap dampers. SDEE 2020, 130, 105989. [CrossRef]

9. Fujita, K.; Yasuda, K.; Kanno, Y.; Takewaki, I. Robustness evaluation of elastoplastic base-isolated high-rise buildings subjected to critical double impulse. Front. Built Environ. 2017, 3, 31. [CrossRef]

10. Anajafi, H.; Poursadr, K.; Roohi, M.; Santini-Bell, E. Effectiveness of seismic isolation for long-period structures subject to far-field and near-field excitations. Front. Built Environ. 2020, 6. [CrossRef]

11. Ponzo, F.C.; Di Cesare, A.; Leccese, G.; Nigro, D. Shaking table tests of a base isolated structure with double concave friction pendulums. Bull. N. Z. Soc. Earthq. Eng. 2015, 48, 136-144. [CrossRef]

12. Quaglini, V.; Dubini, P.; Furinghetti, M.; Pavese, A. Assessment of Scale Effects in the Experimental Evaluation of the Coefficient of Friction of Sliding Isolators. JEE 2019. [CrossRef]

13. Ponzo, F.C.; Di Cesare, A.; Leccese, G.; Nigro, D. Shake table testing on restoring capability of double concave friction pendulum seismic isolation systems. EESD 2017, 46, 2337-2353. [CrossRef]

14. Furinghetti, M.; Pavese, A.; Quaglini, V.; Dubini, P. Experimental Investigation Of The Cyclic Response Of Double Curved Surface Sliders Subjected To Radial And Bidirectional Sliding Motions. SDEE 2019. [CrossRef]

15. Pavese, A.; Furinghetti, M.; Casarotti, C. Investigation of the consequences of mounting laying defects for curved surface slider devices under general seismic input. JEE 2019. [CrossRef]

16. Zayas, V.; Mahin, S.; Constantinou, M.C. Safe and Unsafe Seismically Isolated Structures; PEER Report No. 20016-01; Pacific Earthquake Engineering Research Center: Berkeley, CA, USA, 2016.

17. Ragni, L.; Cardone, D.; Conte, N.; Dall'Asta, A.; Di Cesare, A.; Flora, A.; Leccese, G.; Micozzi, F.; Ponzo, C. Modelling and seismic response analysis of Italian code-conforming base-isolated buildings. JEE 2018, 22 (Suppl. 2), 198-230. [CrossRef]

18. Cardone, D.; Conte, N.; Dall'Asta, A.; Di Cesare, A.; Flora, A.; Lamarucciola, N.; Micozzi, F.; Ponzo, F.C.; Ragni, L. RiNTC-e project: The seismic risk of existing italian rc buildings retrofitted with seismic isolation. In Proceedings of the COMPDYN 2019-7th ECCOMAS Thematic Conference on Computational Methods in SDEE, Crete, Greece, 24-26 June 2019. 
19. Flora, A.; Perrone, G.; Cardone, D. Evaluating Collapse Fragility Curves for Existing Buildings Retrofitted Using Seismic Isolation. Appl. Sci. 2020, 10, 2844. [CrossRef]

20. Iervolino, I.; Spillatura, A.; Bazzurro, P. Seismic Reliability of Code-Conforming Italian Buildings. JEE 2018, 22 (Suppl. 2), 5-7. [CrossRef]

21. Ricci, P.; Manfredi, V.; Noto, F.; Terrenzi, M.; Petrone, C.; Celano, F.; De Risi, M.T.; Camata, G.; Franchin, P.; Magliulo, G.; et al. Modeling and Seismic Response Analysis of Italian Code-Conforming Reinforced Concrete Buildings. JEE 2018, 22 (Suppl. 2), 105-139. [CrossRef]

22. Ricci, P.; Manfredi, V.; Noto, F.; Terrenzi, M.; De Risi, M.T.; Di Domenico, M.; Camata, G.; Franchin, P.; Masi, A.; Mollaioli, F.; et al. RINTC-e: Towards seismic risk assessment of existing residential reinforced concrete buildings in Italy. In Proceedings of the COMPDYN 2019-7th ECCOMAS Thematic Conference on Computational Methods in SDEE, Crete, Greece, $24-26$ June 2019.

23. Ponzo, F.C.; Di Cesare, A.; Telesca, A.; Nigro, D.; Castellano, M.G.; Infanti, S. Influence of DCCSS Bearings Over-Stroke and breakaway on the seismic response of isolated buildings. In Proceedings of the 17th WCEE, Sendai, Japan, 13-18 September 2020.

24. Di Cesare, A.; Ponzo, F.C.; Telesca, A. Improving the earthquake resilience of isolated buildings with double concave curved surface sliders. Eng. Struct. 2020, 111498. [CrossRef]

25. Furinghetti, M.; Yang, T.; Calvi, P.M.; Pavese, A. Dynamic response of curved surface slider devices under severe input motion. In Proceedings of the 17WCEE, Sendai, Japan, 13-18 September 2020.

26. Furinghetti, M.; Yang, T.; Calvi, P.M.; Pavese, A. Experimental evaluation of extra-design displacement capacity for curved surface slider devices. SDEE. Under review.

27. Bao, Y.; Becker, T.C.; Sone, T.; Hamaguchi, H. Experimental study of the effect of restraining rim design on the extreme behavior of pendulum sliding bearings. EESD 2017. [CrossRef]

28. NTC 2018. Norme Tecniche per le Costruzioni; Decreto Ministeriale del 17 Gennaio 2018; Ministero delle Infrastrutture e dei Trasporti: Rome, Italy, 2018.

29. DM 74. Norme Tecniche per la Esecuzione delle opere in Cemento Armato Normale e Precompresso e per le Strutture Metalliche; Decreto Ministeriale del 30 Maggio 1974; Ministero delle Infrastrutture e dei Trasporti: Rome, Italy, 1974.

30. DM 86. Norme Tecniche Relative alle Costruzioni Sismiche; Decreto Ministeriale del 24 Gennaio 1986; Ministero delle Infrastrutture e dei Trasporti: Rome, Italy, 1986.

31. Baraschino, R.; Baltzopoulos, G.; Iervolino, I. R2R-EU: Software for Fragility Fitting and Evaluation of Estimation Uncertainty in Seismic Risk Analysis. SDEE 2020, 132, 106093. [CrossRef]

32. Cornell, C.A.; Krawinkler, H. Progress and Challenges in Seismic Performance Assessment; PEER Center News 3; Pacific Earthquake Engineering Research Center: Berkeley, CA, USA, 2000.

33. Akkar, S.; Bommer, J.J. Empirical Equations for the Prediction of PGA, PGV, and Spectral Accelerations in Europe, the Mediterranean Region, and the Middle East. Seismol. Res. Lett. 2010, 81, 195-206. [CrossRef]

34. Mckenna, F.; Fenves, G.L.; Scott, M.H.; Jeremic, B. Open System for Earthquake Engineering Simulation (OpenSEES); PEER Center, University of California: Berkeley, CA, USA, 2000.

35. Ibarra, L.F.; Medina, R.A.; Krawinkler, H. Hysteretic models that incorporate strength and stiffness deterioration. EESD 2005, 34, 1489-1511. [CrossRef]

36. Decanini, L.D.; Liberatore, L.; Mollaioli, F. Strength and stiffness reduction factors for infilled frames with openings. Earthq. Eng. Eng. Vib. 2014, 13, 437-454. [CrossRef]

37. Kitayama, S.; Constantinou, M.C. Effect of superstructure modeling assumptions on the seismic performance of seismically isolated buildings. EESD 2021. [CrossRef]

38. Ryan, K.L.; Polanco, J. Problems with Rayleigh damping in base-isolated buildings. JSE 2008, 134, 1780-1784. [CrossRef]

39. Anajafi, H.; Medina, R.A.; Santini-Bell, E. Effects of the improper modeling of viscous damping on the first-mode and higher-mode dominated responses of base-isolated buildings. EESD 2020, 49, 51-73. [CrossRef]

40. Constantinou, M.C.; Mokha, A.; Reinhorn, A. Teflon bearings in base isolation. II: Modeling. JSE (ASCE) 1990, 116, 455-474. [CrossRef]

41. Di Cesare, A.; Ponzo, F.C.; Telesca, A.; Nigro, D.; Castellano, M.G.; Infanti, S.; Fichera, S.; Biondi, B. Modelling of the over stroke displacement of curved surface sliders using OpenSEES. In Proceedings of the First Eurasian Conference on OpenSEES, Hong Kong, 20-21 June 2019.

42. ReLUIS-RINTC Workgroup. Results of the 2015-2017 RINTC Project; ReLUIS-RINTC Report; ReLUIS: Naples, Italy, 2018.

43. Ruggieri, S.; Uva, G. Accounting for the Spatial Variability of Seismic Motion in the Pushover Analysis of Regular and Irregular RC Buildings in the New Italian Building Code. Buildings 2020, 10, 177. [CrossRef] 